\title{
Excellence in Lesson Planning: The Purpose and Use of a Micro-uniting Template
}

\author{
Jeanette M. Landin \\ Landmark College
}

For college professors, student engagement is the pinnacle of the teaching experience. The competition with external influences such as social media and internal issues such as interest in the subject being studied can cause students to disengage from classroom sessions and reduce the ability to learn the material. The use of Micro-Uniting as a classroom preparation tool is a key to improve student engagement, to maintain student focus, and to maintain both academic rigor and flexibility. An example of a Micro-United lesson plan and suggestions for use is included.

Keywords: Lesson Planning, Student Engagement, Universal Design, Learning Outcomes, Cognitive Domain, Cognitive Load, Multi-Modal, Teaching, Instruction, Student Success

\section{INTRODUCTION}

Imagine the worst possible class session: an unprepared teacher, disengaged students, and wasted time. That is the nightmare of many, if not most, instructors. Student engagement and learning is the goal in an any college classroom. However, achieving student engagement and promoting mastery of desired learning outcomes to students can be a challenging task for instructors. To help students achieve learning goals, professors need to develop diverse instructional practices that promote engagement as mastery without diminishing academic rigor. A generalized best practice in teaching techniques involves Universal Design (UD) (CAST, 2019). UD is a technique for learning and instruction that involves the use of micro-uniting, multi-modal teaching, and experiential learning opportunities, which is a best practice for instructional design (Stewart, Houghton, \& Rogers, 2015). The use of micro-united (MU) lessons is the key to the deliberate inclusion of multi-modal teaching and desired experiential learning opportunities.

\section{Definition of MU}

A fundamental element in classroom teaching is the breaking down of concepts into manageable, supported units (Allen, 2016). College instructors obtain the information about course learning objectives from the institutionally approved course learning objectives. The challenging part for teachers is using metacognition to determine ways to communicate information and engage students in their learning process (Burcu \& Çetin, 2019). Micro-uniting (MU) of lessons involves breaking learning objectives into very small, highly articulated lessons. The articulation of lessons involves the date of delivery, development of a precise lesson topic, necessary resources, timed delivery elements, leading questions, 
and specifically related homework assignments. An example of an articulated lesson plan is created using a grid similar to the one contained in Figure 1.

\section{FIGURE 1}

\section{AN EXAMPLE OF A MICRO-UNITING TEMPLATE FOR AN ACCOUNTING CLASS}

\begin{tabular}{|c|c|}
\hline Date & $10 / 1 / X X$ \\
\hline Topic & Adjusted Trial Balance \\
\hline Resources & $\begin{array}{l}\text { Unadjusted vs. adjusted trial balance handout, working papers for in-class exercises } \\
\text { and homework }\end{array}$ \\
\hline $\begin{array}{r}\text { Delivery Mode } \\
\text { (lecture, } \\
\text { activities) in } \\
\text { the order of } \\
\text { presentation }\end{array}$ & $\begin{array}{l}\text { 1. (5 mins) Questions, etc. } \\
\text { 2. (10 mins) Activity: Adjustment accounts } \\
\text { 2. (10 mins) Review Adjustments, PR3-1A } \\
\text { 3. (10 mins) Lecture: The Adjusted Trial Balance } \\
\text { 5. ( } 35 \text { mins) PR 3-5B } \\
\text { 5. (5 mins) Wrap-up }\end{array}$ \\
\hline $\begin{array}{r}\text { Leading } \\
\text { Questions }\end{array}$ & $\begin{array}{l}\text { 2. For the account you have been given, a) what account does it pair with for } \\
\text { adjustments, and b) Is the account a debit or credit in the transaction? } \\
\text { 3. What was the purpose of the trial balance? } \\
\text { 3. How will the adjustments affect the trial balance? } \\
\text { 5. How do we prepare the adjusted trial balance? What effect do the adjustments have } \\
\text { on net income? }\end{array}$ \\
\hline Assignments & PR 3-5A, chapter 3 Vocabulary \\
\hline
\end{tabular}

It is important to notice that each section of the template in Figure 1 has a specific, unique function. An understanding of how the MU sections work is an important part of understanding the overarching purpose. The details of each section follow.

\section{Date and Topic}

The date and topic allow the instructor to determine precisely when the lesson will occur and what the focus of the lesson will be. The topic section should be as specific as possible for the MU process to work. For example, in an accounting class, the topic might be a specific process such as performing a bank reconciliation or completing year-end payroll forms. Having a narrow topic allows the instructor to design the unit to meet the needs of the student while remaining on topic during the entire class session.

\section{Resources}

The Resources section allows the instructor to plan for precise tools, websites, handouts, etc., that will enhance student learning of the specific topic. Using the idea of teaching students how to complete yearend payroll forms, the instructor would consider what specific items should be prepared for the class session. In that case, blank forms, specific instructions, and perhaps a sample of a completed form would be appropriate resources. Other items that may be helpful to list as resources are related videos, calculators, etc. The purpose of the resource section is for the instructor to consider and prepare the materials that will work best to meet the class sessions' topic.

\section{Delivery Mode}

The Delivery Mode is an incredibly important section of the lesson plan, and truly is the heart of the MU process. It is in this section of the lesson plan that the instructor will place information about precisely how the class session will flow. Articulation of the Delivery Mode promotes a laser-like focus on the specific sub-topics for the session, allowing for depth but restricting the temptation to engage in 
off-topic discussions. The instructor should use this section to plan specific segments of lecture, activities, discussion, and other relevant items. Again, the purpose of MU in lesson planning is to maintain student engagement; deliberate consideration of how the narrowed topic will be delivered allows the instructor to consider how much time to spend on each piece so that they reach the goal of the lesson.

\section{Leading Questions}

Of all the sections of the MU lesson plan, the Leading Questions require critical thought and can be the most challenging part of planning the lesson. The Leading Questions section promotes the anticipation of questions that the instructor has previously encountered when teaching the topic. Additionally, it promotes meta-teaching, "a teaching process with practice consciously guided by thinking, inspiring teachers to teach more effectively" (Chen, 2013, p. S63). Despite its arduous nature, the Leading Questions are an important part of keeping the lesson on track for students and act as a good prompt when the student conversations either become sidetracked or when additional conversations must be started.

\section{Homework}

The final section of the MU lesson plan is the homework. This is the goal that the instructor strives for in planning lessons and is often viewed as an important part of formative assessment. The homework acts as a bookend of sorts when partnered with the class session's topic and should be thought of as a starting and ending point for the day's activities. If done correctly, the homework will be a natural outgrowth of the student's learning that day.

By using MU, teachers take the lesson planning process to a granular level, which leads to the effective planning of course delivery (Englander, Terragrossa, Wange, \& Wielkopolski, 2012). The MU lesson planning process can be applied at any academic level because of the need to plan lessons for students of any age. The use of MU lesson planning for college courses is a novelty because the style of teaching in college courses varies and lacks what may be construed as a prescriptive nature used in elementary and secondary education courses.

\section{Purpose of MU for College Courses}

According to Simon Sinek (2009), one fundamental question to ask when embarking on a new venture is to determine why it is necessary and worthy of doing. Defining why course planning use MU is important requires introspection by teachers about their purpose. What is the value of devoting time to lesson planning when it might be easier to simply have a topic and just allow the class sessions to progress organically? This is a valid question, and the answer lies in determining the value of the course of action. A college instructor must consider both institutional and their own professional values when deciding how to proceed with any activity, especially lesson planning. It is probably safe to assume that all colleges, universities, and instructors of any level want to deliver high-quality education that students use to improve their lives. With the why question articulated, the next question is how to achieve that goal. MU allows instructors to answer the how question through breaking lessons down to a granular level and examining each piece for purpose and integrity.

Using MU as part of instructional design may appear to require a significant amount of prior planning because the truth is that MU takes time to develop. Articulating a class using MU sometimes takes more time than the actual delivery of the class session. With all the other demands on collegiate instructors' time, why add more time to the process? The short answer is student retention, both of the material and within the college. Well-planned lessons break through the stress that students associate with college courses and may lead to greater satisfaction with their learning, which leads to increased student engagement and higher retention (Cavanaugh, 2016; Farr-Wharton, Charles, Keast, Woolcott, \& Chamberlain, 2018). Therefore, the use of MU as a planning tool becomes an obvious choice as a part of effective instruction. 


\section{Brain-based Reasons for MU Lesson Planning}

The human brain changes at the neural level during the process of learning (Wenger, Brozzoli, Linderberger, \& Lövdén, 2017). Neurons become activated, new information is encoded, and new neural connections are made. The idea of chunking lessons (i.e., organizing the information into small blocks) was a good step toward creating a learning experience in harmony with brain processes (Major \& Calandrino, 2018). The MU approach takes the idea of chunking information one step further because it allows instructors to plan course delivery intentionally, with a focus on the flow of the course.

\section{Chunking of Information and the Cognitive Domain}

Instruction has historically been focused on invoking a student's cognitive domain (Gorski, Caspri, \& Chajut, 2007). This domain focuses on memory and the student's inherent ability to store and retrieve information on demand. It makes sense that the human brain prefers material that is chunked, meaning that information about a single subtopic is gathered and presented at the same time. The MU approach is based on chunking of information, and it also involves the affective domain.

\section{Student Engagement and the Affective Domain}

The affective domain, which is about how students feel about their learning, is often overlooked in college courses (Green \& Batool, 2017). It is very tempting for instructors to convey as much information about a topic as possible in order to meet syllabus demands and to convey the passion they feel for a particular topic. The pitfall is that the enthusiasm for the subject can lead to an overly large amount of information packed into a course. Try as they might, students may remember only the instructor's passion and small amounts of the information presented, overlooking the points that the instructor considers to be the most important. The MU plan helps instructors curb their enthusiasm and focus on what elements of the course will be the most engaging for students. They way they do this is to plan learning activities that will evoke a similar enthusiasm from their students. At the heart of their learning, students to find a topic or discipline about which they can develop a professional passion. The MU lesson planning process engages the affective domain by making the learning manageable and allowing students to understand their instructor's passion for their topic.

\section{Responding to Student Needs}

The beauty of using MU for class session planning is that it allows the instructor the flexibility to respond to student needs while maintaining focus on the lesson plan. The challenge that it common to teachers is how to maintain focus on planned lessons while attending to specific student questions. If an instructor knows from experience that a topic is particularly difficult for students, then time for student questions and additional examples can be incorporated in the lesson plan. Conversely, if the instructor encounters particularly challenging issues, then pieces of the MU lesson plan can be moved, removed, or otherwise changed as necessary. The instructor would note in the bottom section of the MU plan what happened, document any specific circumstances, and adjust future lesson plans accordingly. The purpose of the MU plan is not to over-segment a lesson but to ensure both focus and flexibility in the instructional process.

\section{Effectiveness of Micro-uniting in the College Classroom}

The question is then, how do instructors know that MU of lesson plans works? A common reflection from colleagues has been that it seems to require a lot of extra work to use the MU template instead of using a more simplified list of topics to cover. From personal experience, it is indeed simpler to have a list of topics and homework for each class session. It is also riskier in that class discussions can cause the instructor to become diverted from the original plan, or tangential topics can overtake a discussion, or any unplanned event can potentially derail a class session, wasting the limited time available for working with students.

Another example of the MU lesson plan effectiveness is the block for Resources. It allows the instructor to plan specific resources and to have them ready in advance of the class session. For example, 
if the instructor wished to use a video to explain a topic or offer a specific application of a skill, the instructor would use the Resources section of the MU plan to make a note about the video. Another example would be activities during the class. If a worksheet is necessary for an activity, then the instructor could annotate the MU plan as such. After the class session, the instructor could reflect on the effectiveness of such resources and makes notes for future iterations of the specific lesson.

\section{Recommendations for Implementation and Future Study}

To implement a MU lesson plan takes time at first. When first creating a lesson using the MU lesson plan template (a blank one is located in Appendix A), it requires effort to consider specific lesson goals, class pacing, activities, length of lecture segments, etc. It may seem dauting to try to capture experience with lessons in the MU template and may seem like it stifles creativity. The opposite is actually the truth. The more time an instructor spends planning out the class, the more smoothly the class will flow, making the student's experience of the class richer.

It is best to implement the MU lesson plan one class at a time. Try it for one lesson and see how it works. It works optimally when planning multiple lessons for the same class (e.g., a week or a unit) because then the usefulness of the tool becomes clearer. For example, in teaching a unit about marketing, the MU plan can be used to include lectures about marketing basics, engagement activities to allow students to relating marketing campaigns to their own lives, and in-class assignments to reinforce lessons. The use of the MU plan is aligned with Bruner's spiral curriculum theory and works very well in that context.

For future study, it would be interesting to note contrasts between classes in which a MU plan was implemented and one without it and obtaining student feedback about their experiences of the classes. Another path for future study would be quantitative evaluations of student grades in classes when a MU plan is used versus when it is not used to determine if significant correlations exist. A final recommendation for future study would be instructor-based reflections about their experience with the MU lesson plan and recommendations for improvement of the template.

\section{CONCLUSION}

Multi-modal teaching requires deliberate planning and attention to details. The MU lesson plan is one method that instructors can use to plan their class sessions by creating small, focused pieces of each class that act as the building blocks for each class session. Instructors who use the MU lesson plan can intentionally arrange class sessions to adapt to student or curricular needs, which leads to well-designed instruction and curricular delivery. Most importantly, the needs of both the instructor and the student can be addressed in a MU lesson plan. MU lesson planning takes time, and the potential for increased student engagement and later success is well worth the effort. 


\section{REFERENCES}

About Universal Design for Learning. (2019). Retrieved from http://www.cast.org/our-work/aboutudl.html

Allen, B. (2016). Emerging Strategies for Supporting Student Learning: A Practical Guide for Librarians and Educators. London, UK: Facet Publishing.

Burcu, D., \& Çetin, S. (2019). The effect of a metacognition-based instructional practice on the metacognitive awareness of the prospective teachers. Universal Journal of Educational Research, 7(3), 720-728.

Cavanaugh, S. R. (2016). The spark of learning: Energizing the college classroom with the science of emotion. Morgantown, WV: West Virginia University Press.

Chen, X. (2013). Meta-teaching: Meaning and Strategy. Africa Education Review, 10(1), S63-S74.

Englander, F., Terregrossa, R. A., Wang, Z., \& Wielkopolski, T. (Spring 2012). How college instructors can enhance student achievement: testing a learning styles theory. International Journal of Education Research, 7(1), 1-14.

Farr-Wharton, B., Charles, M. B., Keast, R., Woolcott, G., \& Chamberlain, D. (2018). Why lecturers still matter: the impact of lecturer-student exchange on student engagement and intention to leave university prematurely. Higher Education, 75(1), 167-185.

Gorski, P., Caspri, A., \& Chajut, E. (2007). Elluminate article: Toward a unified theory of instruction in the cognitive domain. International Review of Research in Open and Distance Learning, 8(3).

Green, Z. A., \& Batool, S. (2017). Emotionalized learning experiences: Tapping into the affective domain. Evaluation and Program Planning, 62, 35-48.

Major, A., \& Calandrino, T. (2018). Beyond chunking: Microlearning secrets for effective online design. Distance Learning, 15(2), 27-31.

Sinek, S. (2009) Start with why: How great leaders inspire everyone to take action. New York, NY: Penguin Group (USA).

Stewart, A. C., Houghton, S. M., \& Rogers, P. R. (2015). Instructional design, active learning, and student performance: Using a trading room to teach strategy. Journal of Management Education, 36(6), 753-776.

Wenger, E., Brozzoli, C., Linderberger, U., \& Lövdén, M. (2017). Expansion and renormalization of human brain structure during skill acquisition. Trends in Cognitive Sciences, 21(12), 930-939. 


\section{APPENDIX A \\ THE MICRO-UNITED LESSON PLAN TEMPLATE}

\begin{tabular}{|r|r|}
\hline Date & \\
\hline Topic & \\
\hline Resources & \\
\hline Delivery & \\
Mode & \\
(lecture, & \\
activities) in & \\
the order of & \\
presentation & \\
\hline Leading & \\
Questions & \\
\hline Assignments & \\
\hline
\end{tabular}

